\title{
INQUISIÇÃO NO PERNAMBUCO QUINHENTISTA: O CASO DE FELÍCIA TOURINHO
}

\section{INQUISITION IN PERNAMBUCO IN THE 16TH CENTURY: THE CASE OF FELÍCIA TOURINHO}

\author{
Roberta Cristina da Silva CRUZ*
}

\begin{abstract}
RESUMO: O Tribunal do Santo Ofício em Portugal foi criado em 1536 para averiguar e punir os crimes praticados contra a fé católica. Os agentes inquisitoriais, investidos do papel que julgavam essencial para manter a sociedade longe das influências heréticas, agiram na reorganização da vida religiosa, assim como na "inspeção da fé". Na América portuguesa, apesar da inexistência de um Tribunal Inquisitorial, podemos observar os mesmos objetivos que no reino, através de visitações e de uma rede de agentes estabelecida por diferentes regiões da colônia. O presente trabalho buscará relacionar aspectos da Primeira Visitação do Santo Ofício às suas ações quanto à repressão dos delitos ligados aos desvios de fé. Neste sentido, dividiremos nossa análise em duas partes: primeiro analisaremos como o Santo Ofício agiu para reprimir tais desvios, e depois, o caso de Felícia Tourinho, denunciada por praticar adivinhação. Examinaremos também como a Inquisição portuguesa lidou com esse tipo de delito.
\end{abstract}

Palavras-chave: Inquisição. Adivinhação. Pernambuco

ABSTRACT: The Tribunal of the Holy Office in Portugal was created in 1536 to investigate and punish crimes against the Catholic faith. Inquisitorial agents acted in the reorganization of the religious life, as in "inspection of faith". In Portuguese America, despite the lack of an Inquisitorial Tribunal, was developed the same goals as the kingdom through visitations and a network of agents established in different regions of the colony. This article aims to relate aspects of the First Visitation of the Holy Office to the actions on the repression of offenses related to deviations of faith. In this sense, we will divide our analysis into two parts: First we'll analyze how the Inquisition acted to suppress such deviations, and then, the case of Felicia Tourinho, indicted by divination practices. We will also examine how the Portuguese Inquisition dealt with this type of offence.

Keywords: Inquisition. Divination. Pernambuco.

\section{Primeira Visitação do Santo Ofício}

O visitador Heitor Furtado de Mendonça, desde o momento de sua chegada, provocou medo e comoção entre os colonos, mostrando dessa forma, o grande controle social que a Inquisição exercia. Por meio de visitações, ele levou a presença inquisitorial pela Bahia, Pernambuco, Itamaracá e Paraíba nesse primeiro momento (VAINFAS, 2010). Segundo Bethencourt, para os membros dos tribunais da Inquisição,

\footnotetext{
* Mestranda do Programa de Pós Graduação em História Social da Universidade Federal do Rio de Janeiro (UFRJ). Bolsista Capes. E-mail: robertacrz@gmail.com.
} 
seu papel seria fundamental, pois sem eles, a cristandade teria sido "infectada" e o mundo dominado pelo demônio. A heresia perverteria os costumes e a sociedade como um todo (BETHENCOURT, 2000, p. 356-357).

O tribunal da Inquisição em Portugal, criado em 1536, tem íntima ligação com o contexto político e social de Castela e Aragão que teve a criação de seu Tribunal em 1478. A partir de 1492, os judeus foram expulsos da Espanha ou forçados a se converterem ao cristianismo. Por causa deste quadro de perseguições antissemitas, muitos judeus e cristãos-novos refugiaram-se em Portugal. $\mathrm{O}$ aumento da população judaica e as pressões dos monarcas espanhóis em troca do casamento de D. Manuel I com a infanta D. Isabel fizeram com que o rei português criasse medidas para a expulsão dos judeus e muçulmanos (MARCOCCI; PAIVA, 2013, p. 49-62).

Entretanto, ao mesmo tempo, o monarca tomou medidas que procuravam dificultar a saída dos judeus, por serem extremamente importantes no financiamento de atividades ultramarinas, culminando na conversão forçada em 1497. Logo o estigma e a perseguição antes direcionadas aos judeus foram transferidas para os cristãos-novos, apesar do rei ter promovido uma política ambígua em relação a eles, ora os beneficiando, ora limitando sua liberdade de ir e vir. Esta situação ambígua em relação aos cristãos-novos permaneceu durante o reinado de D. Manuel I e continuou no de D. João III. A título de introdução, não nos deteremos a explicar o processo de instituição do Tribunal português, mas é importante ressaltar que sua instituição foi marcada por um processo de perseguição aos judeus e depois aos cristãos-novos, culminando na instituição do Tribunal no reinado de D. João III (MARCOCCI; PAIVA, 2013, p. 50).

Os judeus e cristãos-novos foram os mais perseguidos pelo Santo Ofício, tendo figurado o maior número de processados e executados. Neste sentido, Federico Palomo acrescenta que o aumento de judeus e conversos em Portugal teria posto em causa a homogeneidade confessional do reino, que teria que ser controlada, sendo a Inquisição um instrumento para isso. Além disso, o Tribunal seria uma instância legitimadora do disciplinamento social pós-tridentino (PALOMO, 2006, p. 26-27).

Quanto à feitiçaria, no caso português, era considerada um delito de menor gravidade tanto pela inquisição quanto pelas autoridades eclesiásticas, diferentemente do que ocorreu em outras partes do continente europeu. Bethencourt nos apresenta uma espécie de hierarquia de "delitos" que apesar de todos serem perseguidos e fazerem parte do foro inquisitorial, uns tinham maior relevância que outros (BETHENCOURT, 2004). Em primeiro lugar estariam os “crimes" ligados ao judaísmo, como já dissemos 
anteriormente, ao maometismo e ao luteranismo. Porém, o luteranismo não teve uma penetração expressiva na Península Ibérica como em outras partes do continente, tendo a repressão ocorrido mais restrita aos estrangeiros e para seguir as ordens de Roma. Depois desses, vinham os ligados a feitiçaria, adivinhações e cultos de matrizes medievais europeias (pagãos). Na verdade, os diferentes modelos de cristianização já teriam a benevolência quanto à repressão aos vestígios de crenças pagãs. No que tange a inquisição, a repressão foi relativamente leve (SOUZA, 2009).

Desta forma, na década de 1590 a Inquisição que até então se concentrava em Portugal ganhou o ultramar. Em 1591, se deu por inaugurada a ação inquisitorial em terras brasileiras com a chegada do visitador Heitor Furtado de Mendonça a Bahia. Nesse período após o Concílio de Trento, marco da Contra Reforma, a inquisição tinha uma preocupação a mais do que as heresias acerca do judaísmo. As faltas contra os dogmas e princípios da Igreja ganharam importância (VAINFAS, 1997, p. 18). Entretanto, em terras coloniais, a ação inquisitorial não foi tão forte quanto na metrópole. Não foi instituído um tribunal em terras brasileiras. A América portuguesa esteve durante todo o período colonial submetida ao tribunal lisboeta. Os tribunais instituídos foram os de Lisboa, Évora, Coimbra e Goa. Por meio de visitações, principalmente nos séculos XVI e XVII, o Santo Ofício conseguiu exercer o seu domínio, mas sobretudo no seiscentos as visitações desse tipo direcionadas tanto à colônia quanto na metrópole se encerram. Isso ocorre não somente devido às guerras de Restauração, mas também por que a rede de familiares e comissários começou a ser mais estruturada (MARCOCCI; PAIVA, 2013, p. 305-329).

$\mathrm{Na}$ América, as autoridades eclesiásticas e inquisitoriais procuraram impor o modelo demonológico europeu coibindo idolatrias e superstições por mais que não tivessem sido o foco persecutório principal em Portugal. Com os ritos ameríndios e africanos, a demonologia europeia se viu fortalecida, sendo a colônia um "laboratório prático" para os manuais europeus (SOUZA, 1993). Além disso, nas primeiras décadas do século XVI, o Brasil foi um local atraente para os recém conversos, atraídos pelas possibilidades de ganhos econômicos e para fugir da perseguição (HERMANN, 2009, p. 339). No Brasil, a Inquisição causava pavor. Nos Editais da Fé ou Monitórios, constavam as práticas que estavam sob a jurisdição inquisitorial. Através deles, os colonos eram convocados a confessarem suas culpas e delatarem quem as tivesse cometido, independentemente da posição social da pessoa (GORENSTEIN, 2005, p. 320-322). Porém, o visitador geralmente se associava às elites. Em 1593, Furtado de 
Mendonça seguiu para Pernambuco instalando a visitação em Olinda, local com grande concentração de engenhos e, consequentemente, crescimento econômico.

Pernambuco, capitania concedida a Duarte Coelho em 1534 é a que tinha os primeiros engenhos de açúcar fora de São Vicente. No livro de organização de José Gonsalves de Mello, sobre as denunciações pernambucanas, o autor nos informa sobre as impressões de Fernão Cardim, padre jesuíta português, em inscritos de dez anos antes da visitação:

\begin{abstract}
'A gente da terra é honrada; há homens grossos de quarenta, cinqüenta, e oitenta mil cruzados de seu' - Tanto os homens, como as mulheres e seus filhos vestiam-se de toda a sorte de veludos, damascos e outras sedas e nisso opinava o jesuíta que praticam excessos. Os homens, ao seu parecer eram tão briosos que compravam ginetes de duzentos e trezentos cruzados, e alguns possuíam três, quatro cavalos de preço. Era a vaidade que se achava mais em Pernambuco do que em Lisboa, notava o censor (GARCIA, 1984, p. 10).
\end{abstract}

Gabriel Soares em seu Tratado Descriptivo do Brasil de 1587, apesar de denunciar o pouco apoio que a colônia teve por parte da Metrópole por muitos anos, relata:

É tão poderosa essa capitania que ha n'ella mais de cem homens que tem de
mil até cinco mil cruzados de renda, e alguns de oito, dez mil cruzados.
D'esta terra sahiram muitos homens ricos para estes reinos que foram á ella
muito pobres, com os quaes entram cada anno d'esta capitania quarenta e
cincoenta navios carregados de assucar e páo-brasil, o qual é o mais fino que
se acha em toda a costa... E parece que será tão rica e tão poderosa, d'onde
sahem tantos provimentos para estes reinos, que se devia de ter mais conta
com a fortificação d'ella, e não consentir que esteja arriscada a um corsário a
saquear e destruir, o que se póde atalhar com pouca despeza e menos trabalho
(SOUSA, 1938, p. 29).

Leonardo Dantas Silva do Instituto Histórico e Geográfico Brasileiro na introdução do livro de José Antônio Gonsalves de Mello, menciona que em 1570 viviam no Brasil entre 2000 e 3000 escravos trabalhando nas lavouras de cana-deaçúcar. Entretanto, o número de cativos cresce assustadoramente, segundo alguns autores, no final do século XVI com a importação de 3000 negros da Guiné para servirem nas lavouras da Bahia e de Pernambuco. No apogeu da produção do produto, no século XVII, a importação de escravos chega a cerca de 50000 negros, em sua maioria antes de 1640 (MELLO, 2004, p. 15).

Desta forma, podemos observar a prosperidade pernambucana deste período. Por essa razão e pelo afastamento geográfico em relação à metrópole, o Brasil, segundo Gonsalves de Mello, tornou-se uma alternativa para os grupos perseguidos pela Inquisição portuguesa. Dentre esses grupos sublinham-se os judeus e cristãos-novos, já tradicionalmente perseguidos no contexto ibérico. Além de ser uma alternativa a 
perseguição, o local era também uma zona de degredo para os que já haviam sido penitenciados pelo Santo Ofício (MELLO, 1984, p. 20). Após a natural opressão ao judaísmo, o visitador deveria "fiscalizar" e repreender os reincidentes, feiticeiros, bruxos, bígamos, os que liam os livros reprovados pela Igreja e os demais desviantes (VAINFAS, 2010).

Neste momento em que a colonização não tinha muitos anos, os desvios de moral e de fé já eram grandes devido à estrutura eclesiástica incipiente (HERMANN, 2009, p. 340). Tantos os desvios remanescentes de costumes pagãos europeus quanto às práticas desviantes judaicas tinham meio propício para ocorrerem (SOUZA, 2009). Neste contexto, em 21 de setembro de 1593 o visitador Heitor Furtado de Mendonça chegou ao porto de Recife, recepcionado pelas "melhores" famílias da terra, após dois anos de experiência na Bahia. Um mês após sua chegada, instalou a inquisição em Olinda em 24 de outubro. Como de praxe, era afixado o edital da fé fazendo com que as pessoas confessassem suas culpas e denunciassem quem tivesse cometido algum crime. Depois, lia-se o Monitório, que constava os crimes ou indícios que cabia ao Santo Ofício julgar, como as já citadas heresias contra a fé católica e a moral por ela pregada, como explicado anteriormente (VAINFAS, 2002, p. 143-160).

Após as denúncias e confissões, cabia ao visitador determinar a prisão do acusado, que era embarcado para o Reino, com o processo, para os cárceres da inquisição de Lisboa “... cuja jurisdição pertencia a colônia do Brasil para posterior e final julgamento, sendo que a instrução e o julgamento se fazia no próprio processo iniciado no Brasil." (MELLO, 1991, p. 369). Porém, muitas pessoas eram presas e julgadas na colônia. Segundo Gonsalves de Mello, o visitador solicitou ao Conselho Geral do Santo Ofício a fundação de um tribunal em terras brasílicas. Porém, como a solicitação foi negada, o Furtado de Mendonça adquiriu o direito de julgar na colônia os culpados que recebessem abjuração de levi.

Quanto aos processos, estavam organizados no estilo judicial da Inquisição metropolitana: 
Santo Ofício, que em Olinda durante a Visitação, naqueles anos de 1593 a 1595, era o licenciado padre Diogo Bahia, que advogava na então Vila e fora convocado pelo visitador para essa função. Ao libelo o acusado respondia com sua defesa (designada 'contrariedades') também por intermédio de advogado, emprego que em Olinda, então, foi desempenhado pelo licenciado Jorge Barbosa Coutinho, 'letrado jurista advogado' na Vila. Há casos em que as 'contrariedades' eram seguidas por depoimentos de testemunhas de defesa, designadas pelo indicado. Seguia-se a apresentação a ele dos 'ditos' das testemunhas da justiça, isto é, de extratos dos depoimentos dos denunciantes, sem indicação do nome destes e de circunstâncias que pudessem identificálos. Novas 'contrariedades' e, as vezes, novas testemunhas de defesa. Finalmente o processo ia a julgamento perante um tribunal composto, em Olinda, do bispo da Bahia (D. Antônio Barreiros, que então estava na Capitania de Pernambuco), do visitador e dos padres teólogos seus assessores, geralmente em número de três (ocasionalmente dois ou, mesmo quatro), pertencentes a Ordens Religiosas estabelecidas em Olinda: os jesuítas, os franciscanos, os beneditinos e os carmelitas, sendo que daqueles primeiros eram dois os assessores na totalidade dos casos e um de cada uma das demais.

\section{$(\ldots)$}

Exarada a sentença, assinada pelos presentes ao julgamento, lavrara-se o acórdão respectivo subscrito apenas pelo visitador, no qual era tornada pública a sentença, concluindo-se o processo com o termo de abjuração do culpado, abjuração que podia ser feita apenas perante a mesa do tribunal ou em penitência pública, em auto-de-fé (MELLO, 1991, p. 371-373).

Apesar do tribunal considerar as denúncias e ter como princípio julgar os erros

cometidos por todos os indivíduos, os julgadores acabavam levando em consideração a idade, o sexo e a condição social dos culpados. Quanto as penas, poderiam ser admoestação e repreensões feitas perante o visitador, acrescidas de penitências espirituais, até condenação em auto-de-fé, embora, na colônia, não tenham ocorrido execuções de penas capitais nem julgamento de cristãos-novos, que eram enviados à Lisboa. Em certos casos, o julgamento incluía penas pecuniárias para as despesas do Santo Ofício. Alguns réus chegaram ainda a ser açoitados pelas ruas de Olinda e outros foram condenados às galés (MELLO, 1991, p. 373).

\section{O caso de Felícia Tourinho}

A partir da conjuntura até aqui analisada, buscaremos analisar o caso de Felícia Tourinho denunciada na primeira visitação. Todavia, cabe ressaltar as reflexões de Joan Scott e Judith Butler sobre o conceito de gênero. A análise de Joan Scott, aponta o conceito de gênero como uma forma de se observar as relações de poder entre os sexos em diversos níveis como o normativo e o simbólico (SCOTT, 1995, p. 21). Para a autora, a categoria de gênero não pode ser analisada sem que levemos em conta o tempo histórico e as relações sociais que permeiam a análise. 
Só podemos escrever a história desse processo se reconhecermos que 'homem' e 'mulher' são ao mesmo tempo categorias vazias e transbordantes; vazias porque elas não tem nenhum significado definitivo e transcendente; transbordantes porque mesmo quando parecem fixadas, elas contém ainda dentro delas definições alternativas negadas ou reprimidas (SCOTT, 1995, p. 28).

Neste sentido, a autora vai de encontro às análises de Judith Butler que percebe as categorias de "feminino" e "masculino" como vazias se não levarmos em conta outras conjunturas de um determinado contexto social. Estas teorias sobre o gênero devem ser analisadas de acordo com outros eixos de análise, desconstruindo a imagem de falsa uniformidade que estas categorias apresentariam (BUTLER, 2003, p. 19). Laqueur menciona que ser homem ou mulher era uma posição social e não somente sêlo organicamente (LAQUEUER, 2001, p. 177). Por esta razão, buscaremos analisar o caso de Felícia relacionando-o com o papel social que ela ocupava dentro da sociedade em que viveu.

No dia 28 de janeiro de 1594 na Vila de Olinda, Domingas Jorge, cristã velha, natural de Monte Rei, reino de Galiza, se apresentou perante o visitador Heitor Furtado de Mendonça para denunciar que há 9 ou 10 anos antes, quando estava presa na cadeia pública por estar amancebada com um homem casado, também estava presa Felícia Tourinho, detida por dar uma bofetada em uma mulher honrada dentro de uma Igreja.

Primeiramente, um fato que chama atenção já é a primeira página do processo em que está escrito "Felícia Tourinho - mulher parda" (IANTT, doc. 1268). Apesar do tribunal ter como princípio julgar todos independentemente do sexo ou nível social na prática não era o que ocorria. A posição social contava muito, tanto da parte do denunciante quanto a do denunciado. Dependendo dessa posição, os inquisidores poderiam decidir quem seria mais confiável, quem estaria dizendo a verdade ou qual pena dar. Se um nobre, o auto-de-fé era privado. Se um plebeu, um auto público. Por esta razão, Felícia, mulher e parda era duplamente estigmatizada.

As mulheres europeias no período estudado eram retratadas pelos letrados da época como inferiores aos homens. O mito bíblico de Eva concebida a partir da costela de Adão teria prevalecido sobre outros em que os dois teriam sido criados ao mesmo tempo. No campo do direito, as restrições às atividades, e até mesmo a insubordinação feminina frente ao marido eram notórias. A submissão feminina estava altamente vinculadas a sua honra (WIESNER, 2000). Afinal, elas estariam mais propensas a praticar pecados por serem mulheres. Por esta razão, a vigilância de um homem (pai, marido ou confessor) era necessária (LAVRIN, 2008, p. 109). 
Além disso, a leitura da bíblia de uma forma misógina apresentava um modelo de santidade na figura de Maria em que a mulher alcançaria a santidade através da figura de virgem ou de mãe (SILVA, 2011). Por esta razão, muitas famílias nobres, quando tinham muitas filhas e faltavam perspectivas para a realização de bons casamentos, faziam com que algumas entrassem nos conventos para manter sua honra e a de sua família (LAVEN, 2003). Já as que se casavam, deviam demonstrar sua obediência ao marido e demonstrar sua fé por outras formas de devoção (TAVARES, 2002, p. 150-153).

Na América Portuguesa, de acordo com Mary Del Priore, as mulheres geralmente analfabetas e subordinadas aos homens viviam restritas à vida doméstica. Segundo a autora, as escravas, suas descendentes e mulheres brancas pobres acabavam muitas vezes tornando-se mancebas ou concubinas para poderem resistir às más condições de vida. Porém, elas tinham um papel na expansão demográfica necessária para efetivação da colonização. Era preciso incentivar a criação de famílias. Por outro, povoar a colônia (DEL PRIORE, 1993). A visão misógina em relação às mulheres também prevaleceu no ultramar. No caso de Felícia, além de ser estigmatizada por ser mulher, ainda o era por ser parda, de poucas posses e filha bastarda de um clérigo (SOUZA, 2009, p. 210-214).

Em Portugal, a situação econômica de pessoas denunciadas por praticarem ritos ligados à magia, geralmente era humilde, apesar das feiticeiras serem procuradas por pessoas de todos os níveis sociais. A maioria das processadas eram mulheres e, geralmente, não viviam isoladas da sociedade como o estereótipo poderia sugerir (BETHENCOURT, 2004, p. 203-218). Quanto à situação de pobreza,

Basicamente duas explicações têm sido adiantadas para justificar esta
situação de pobreza que afecta a maioria dos acusados. Por um lado, ela
tornava-os mais vulneráveis e impotentes, pelo que eram o alvo preferido das
comunidades quando se tratava de justificar alguma desgraça. Por outro lado,
esta sua pobreza provocava uma situação de dependência que obrigava à
solidariedade comunitária, pelo que estas acusações eram uma forma de a
comunidade se libertar de um elemento que a sobrecarregava (PAIVA, 1992,
p. 192-193).

A autora insiste que as mulheres no núcleo familiar ou por redes de solidariedade conseguiram adquirir importância dentro da empreitada colonizadora. Ao dizer isso vai de encontro a Gilberto Freyre que em Casa-Grande e Senzala examina o caráter patriarcal da família brasileira e a importância da formação delas para a construção dos primeiros núcleos de povoamento. Priorizando a integração entre o triângulo Casa Grande/ Senzala/ Capela, o autor enfatiza a estrutura familiar dentro do 
engenho (na sociedade patriarcal de Antigo Regime) para a colonização do Brasil. Isso porque no Brasil se desenvolveu bastante os templos privados, subordinando o capelão ao chefe de família (FREYRE, 1983).

A ideia da importância da miscigenação como elemento importante para a colonização brasileira postulada por Freyre, nos apresentam um caminho interessante para entender o caso de Felícia. Ao traçarem a genealogia da denunciada, diz-se que Felícia é mulata, filha de um clérigo chamado Gaspar Tourinho, homem branco, cristão velho e de uma preta forra chamada Antônia Vaz, não conhecera seus avós, tinha um tio, irmão de seu pai, Baltazar Tourinho e tinha um irmão em Porto Seguro, mameluco, filho de seu pai e de uma brasília ${ }^{l}$ chamado Alexandre Tourinho. Além do que já discutimos sobre a importância da miscibilidade portuguesa para a formação das famílias coloniais e da figura da mulher para o povoamento colonial, aqui encontramos uma outra especificidade colonial: os desvios do clero. Longe da metrópole, muitos clérigos que atuavam na colônia eram muito pouco instruído a respeito dos desígnios católicos. Dentro das Igrejas, um dos espaços de sociabilidade mais importantes na colônia, acontecia a interação entre mulheres e padres, sobretudo no momento da confissão. As negras muitas vezes acabavam convivendo com os padres ao trabalharem nas tarefas coloniais. Como diz Del Priore: “Um outro problema a ser enfrentado pela Igreja, em sua tortuosa tentativa de adestrar os corpos e os desejos na colônia, foi a incontinência de homens religiosos ainda não identificados com as regras do celibato, impostas pelo Concílio Tridentino.”(DEL PRIORE, 1993, p. 61).

Retornando ao caso de Felícia, Domingas disse ao inquisidor que um dia viu que Felícia tomou uma tesoura e a empregou em um chapim e com os dedos mostradores postos de baixo dos anéis, a levantou dizendo as palavras: “diabo guedelhudo, diabo orelhudo, diabo felpudo, tu me digas se vai foam ${ }^{2}$ por tal parte, digo por tal caminho (que era um homem do qual queria saber se ia onde ela tinha dito que havia de ir) se isto é verdade tu faças andar isto, se não é verdade, não o faças andar." (IANTT, doc. 1268). Depois a denunciante constatou que o tal fulano realmente tinha ido ao tal local.

A partir da denúncia, Felícia é presa, porém dizia não lembrar do que a poderia ter levado ao Santo Ofício. Depois de muito "examinar sua consciência", em 13 de maio de 1595 Felícia diz perante a mesa inquisitorial que lembrara que quando estava presa há 14 anos conheceu uma mulher na prisão que não lembrava o nome, mas que o sobrenome era Figueiredo, que fez adivinhações usando o chapim e a tesoura. Depois de 
aprender com a outra detenta, Felícia se utiliza do mesmo ato para saber se sua sentença sairia boa ou não dizendo:

\begin{abstract}
eu te esconjuro com São Pedro, com São Paulo, e o diabo felpudo, e o guedelhudo que tu me digas a verdade que te quero perguntar se a minha sentença a de sair boa ou má e, se verdade, que há de sair boa andares, se não houver de sair boa, não andares, e isto fez na dita cadeia uma vez e não lhe andou a tesoura pelo que ela ficou cuidando que lhe sairia ruim a sentença a qual the saiu com dez anos de degredo (...) pelo dito caso de dar a dita bofetada na Igreja a qual sentença ela teve por ruim... (IANTT, doc. 1268).
\end{abstract}

A partir deste relato, o inquisidor pergunta qual era a intenção de Felícia ao fazer tal ato. Se ela achava que o Diabo iria ali aparecer para fazer a tesoura se mover. Então, a ré responde “....mas que quando ela fez a dita sorte com as ditas palavras cuidava ela ré que lhe se houve de sair-lhe boa sentença que o diabo lhe viria ali fazer andar a tesoura e que depois que ela fez a dita sorte e viu que lhe não andava disse ela para a dita Figueredo: creio eu em deus...” (IANTT, doc. 1268).

Desta forma, percebemos que sua visão de Diabo era fortemente marcada pela religiosidade popular européia como a grande parte dos casos de feitiçaria desse momento no Brasil. Se recorria tanto a Deus quanto ao Diabo para adivinhações e magias. Visão do Diabo esta muito menos temida do que a Igreja pregava, se ligando muito mais aos cultos politeístas antigos do que a visão moderna de luta contra o bem e o mal. Na verdade, o Diabo seria mais um Deus a ser cultuado (SOUZA, 2009, p. 184202). A relação do homem com os seus intentos se daria por uma multidão de espíritos (anjos, demônios santos...) intercessores (BETHENCOURT, 2004).

Apesar do que Felícia diz, o inquisidor insistiu em saber se ela realmente achava que o diabo poderia saber do futuro. A ré diz que achava que sim, mas que agora que já tinha mais idade, entendia que só quem sabe do futuro é deus. Disse também que realizou estas adivinhações somente nas vezes mencionadas, enquanto estava presa, não sabendo que aquilo era grave pecado. Perguntada sobre a doutrina cristã, benzeu-se, disse o pai nosso, a ave Maria bem e o Credo com certa dificuldade, dizendo não saber mais nada sobre a doutrina com mais profundidade. Então, ela foi instruída a aprender sobre os desígnios católicos. No desenrolar do processo, ela diz não ter conhecimento de que fazer tais adivinhações se tratava de grave pecado.

Daniela Calainho constata que

Além das influências diabólicas, a Inquisição atentou sempre para a difusão e a origem das práticas e crenças dos negros e mulatos com as quais se deparava em suas argüições, sendo constantes certas indagações: onde aprendeu este ou aquele feitiço ou oração, e se ensinou a mais alguém e quem foi; se induziu outra pessoa a firmar pacto com o Diabo; quantos e quem foram curados; de onde vieram as mandingas, quem eram seus usuários, no 
Brasil e em Portugal. A postura do Tribunal era deter os avanços das práticas heréticas e tentar dominar o espaço onde poderiam atuar (CALAINHO, 2008, p. 228).

Desta forma, ao levarem em conta que a ré era jovem e não sabia que estava cometendo um erro grave, foi escusada de penitência pública recebendo abjuração de Levi no dia 7 de julho de 1595, pena muito comum nesses casos. Foi condenada a fazer penitências espirituais, rezar o rosário nas principais festas cristãs e que pagasse dez cruzados pelos custos do Santo Ofício, pena relevante para uma mulher sem recursos, mas não tão severa quanto acontecia em outros casos.

\section{Considerações Finais}

No caso de Felícia percebemos que em todo momento ela é questionada sobre sua intenção em fazer a prática de adivinhação invocando o diabo. Se ela realmente queria fazer com que o demônio ali aparecesse. Como a ré confessou que era sua intenção, mas que fez isso por ser muito nova e depois assumiu o compromisso de aprender a doutrina católica, não recebeu uma pena pesada, apesar de não ser irrelevante para uma pessoa de parcos recursos.

A visitação procurou, por um lado, disciplinar a fé e a moral dos habitantes coloniais e metropolitanos e, por outro, perseguir aqueles que mais "incomodavam" a Coroa: no caso ibérico, os judeus e cristãos-novos. Essa perseguição ao judaísmo não foi diferente na possessão ultramarina americana. Desta forma, e por tudo o mais que já analisamos, os adivinhos e feiticeiros acabavam ganhando um papel de menor destaque do que as vítimas que seguiam crenças judaicas.

Entretanto, apesar da pena mais leve dada aos casos de feitiçaria e adivinhações, como o de Felícia, o tribunal, por se tratar de uma instituição típica de Antigo Regime, julgava seus réus atentando para:

...um sentido peculiar de justiça dos tribunais no Antigo Regime. Um
conceito de justiça que desconhecia 'direitos humanos' pressupunha que os
homens eram desiguais perante a lei, uns porque eram nobres, outros porque
plebeus, uns porque tinham sangue limpo, outros porque o tinham 'infecto'.
Um conceito de justiça que podia condenar por presunção de culpa,
dispensando provas, ao arbítrio dos juízes. Um conceito de justiça que mal se
diferenciava da idéia de castigo. Justitia, castigo. Justiçar, castigar
(VAINFAS, 2010, p. 225).

Felícia confessou suas culpas, pagou as custas do processo e recebeu a abjuração de levi. $\mathrm{O}$ processo é relativamente curto, pois ela admitiu seu erro e prometeu não cometê-lo novamente. Lina Gorenstein analisa o caso de Tereza Paes de Jesus que “... 
acreditava em Santo Moisés e na Santa Ester, santos adequados à sua criação: filha de mãe cristã-velha, batizada, crismada e tendo crescido como católica, ao ser apresentada à crença na Lei de Moisés e à rainha Ester, transformou-os em santos - a eles pedia o que mais desejava: ser rica." (GORENSTEIN, 2005, p. 369). Ela foi enviada para Lisboa, condenada pelo Santo Ofício e "relaxada à justiça secular". Apesar do caso ter ocorrido no Rio de Janeiro do século XVIII, é relevante para enriquecer a análise até aqui apresentada. Parte da condenação de Tereza pode ter sido por sua teimosia em admitir não ver mal em realizar tais práticas. Como já discutimos até aqui, a mulher deveria ser submissa, não só ao seu esposo, mas também à Igreja. A insubmissão lhe custou a vida, enquanto Felícia conseguiu ser liberada com relativa rapidez. Podemos concluir também que o rito que Felícia desenvolveu está ligado às tradições pagãs europeias, como Laura de Mello e Souza evidencia ser comum para o quinhentos, enquanto os de Tereza ligavam-se às práticas judaicas (SOUZA, 2009). Desta forma, o "delito" cometido pela primeira era de menor gravidade dentro da "hierarquia" inquisitorial.

\section{Referências}

\section{Fonte Manuscrita}

IANTT, Inquisição de Lisboa, doc. 1268.

\section{Fontes Impressas}

MELLO, Jose Antonio Gonsalves de (org). Denunciações e Confissões de Pernambuco, 1593-1595: primeira visitação do Santo Ofício as partes do Brasil. Recife: Fundação do Patrimônio Histórico e Artístico de Pernambuco, Diretoria de Assuntos Culturais, 1984.

Fontes para a História do Brasil holandês. A economia açucareira. 2.ed. Recife: CEPE, 2004, p. XV.

SOUSA, Gabriel Soares. Tratado Descriptivo do Brasil em 1587. 3.ed. São Paulo: Companhia Editora Nacional, 1938.

\section{Referências Bibliográficas}

BETHENCOURT, Francisco. História das Inquisições: Portugal, Espanha e Itália Séculos XV-XIX. São Paulo: Companhia das Letras, 2000. 
O imaginário da magia: Feitiçaria, adivinhos e curandeiros em Portugal no século XVI. São Paulo: Companhia das Letras, 2004.

BOXER, Charles Ralph. O Império Marítimo Português, 1415-1825. Tradução de Inês da Silva. Lisboa: Edições 70, [19--].

BUTLER, Judith. Problemas de gênero: feminismo e subversão de identidade. Rio de Janeiro: Civilização Brasileira, 2003.

CALAINHO, Daniela Buono. Metrópole das Mandingas: Religiosidade Negra e Inquisição Portuguesa no Antigo Regime. Rio de Janeiro: Garamond, 2008.

DEL PRIORE, Mary. Ao Sul do Corpo: Condição feminina, maternidades e mentalidades no Brasil Colônia. Rio de Janeiro: José Olympio; Brasília, DF: Edunb, 1993.

FREYRE, Gilberto. Casa Grande \& Senzala: formação da família brasileira sob regime da economia patriarcal. 22 ed. Rio de Janeiro: Livraria José Olympio, 1983.

GONÇALVES, Regina Célia. Guerras e Açúcares: Políticas e economia na capitania 1585-1630. Bauru: Edusc, 2007.

GORENSTEIN, Lina. O criptojudaísmo. In: A Inquisição contra as mulheres: Rio de Janeiro, séculos XVII e XVIII. São Paulo: Humanitas: Fapesp, 2005. p. 320-322.

HERMANN, Jacqueline. "As metamorfoses da espera: messianismo judaico, cristãosnovos e sebastianismo no Brasil colonial". In: Doré, Andréa; Santos, Antonio Cesar de Almeida (Orgs.). Temas setecentistas: governos e populações no Império Português. Curitiba: UFPR-SCHLA; Fundação Araucária, 2009.

LAQUEUR, Thomas. Inventando o sexo: corpo e gênero dos gregos a Freud. Rio de Janeiro: Relume Dumará, 2001.

LAVEN, Mary. Virgens de Veneza: vidas enclausuradas e quebra de votos no convento renascentista. Rio de Janeiro: Imago, 2003.

LAVRIN, Asunción. Brides of Christ: Conventual Life in Colonial Mexico. Stanford: Stanford University Press, 2008.

MARCOCCI, Giuseppe; PAIVA, José Pedro. História da Inquisição Portuguesa (1536-1821). Lisboa: Esfera dos Livros, 2013.

MELLO, José Antônio Gonsalves de. "Um tribunal da Inquisição em Olinda, Pernambuco (1594-1595)". In: Revista da Universidade de Coimbra, ano 1991, Vol. XXXVI. 
PAIVA, José Pedro. Práticas e crenças mágicas. O medo e a necessidade dos mágicos na diocese de Coimbra (1650 - 1740). Coimbra: Minerva, 1992.p.192-193.

PALOMO, Federico. A Contra-Reforma em Portugal (1540-1700). Lisboa: Livros Horizonte, 2006.

SCOTT, Joan Wallach. Gênero: uma categoria útil de análise histórica. Educação e sociedade. Porto Alegre, n. 16, v. 2, 1995.

SILVA, Ricardo Manuel Alves da. Casar com Deus: vivências religiosas e espirituais femininas na Braga moderna. Tese de Doutoramento em História apresentada à Universidade do Minho. Braga, 2011.

SOUZA, Laura de Mello. O Diabo e a Terra de Santa Cruz: feitiçaria e religiosidade popular no Brasil colonial. São Paulo: Companhia das Letras, 2009.

Inferno atlântico: demonologia e colonização, séculos XVI-XVIII. São Paulo: Cia das Letras, 1993.

TAVARES, Pedro Vilas Boas. Beatas, inquisidores e teólogos. Reação portuguesa a Miguel de Molinos. Dissertação de Doutoramento em Cultura Portuguesa apresentada à Faculdade de Letras da Universidade do Porto. Porto, 2002, 2 v.

VAINFAS, Ronaldo. Trópico dos Pecados: Moral, sexualidade e Inquisição no Brasil. Rio de Janeiro: Civilização Brasileira, 2010.

Confissões da Bahia: Santo Ofício da Inquisição de Lisboa. São Paulo, Cia das Letras, 1997. p. 18.

. “A Inquisição e o cristão-novo no Brasil Colonial". In: PEREIRA, Paulo Roberto (Org.). Brasiliana da Biblioteca Nacional: Guias das fontes sobre o Brasil. Rio de Janeiro: Nova Fronteira, 2002, v. 1.

Jerusalém Colonial: Judeus portugueses no Brasil Holandês. Rio de Janeiro: Civilização Brasileira, 2010. p. 225.

WIESNER, Merry E. Women and Gender in Early Modern Europe. Cambridge: Cambridge University Press, 2000. 


\section{Notas:}

${ }^{1}$ Termo para designar as índias.

${ }^{2}$ Termo para designar fulano.

[Recebido: 12 out. 2013 / Aceito: 07 dez. 2013] 